\title{
Efetividade deliberativa em conselhos municipais de saneamento e de saúde: um estudo em Belo Horizonte-MG e em Belém-PA
}

\author{
Deliberative effectiveness in municipal sanitation and health \\ councils: a study in Belo Horizonte-MG and in Belém-PA
}

Cezarina Maria Nobre Souza (https://orcid.org/0000-0002-2430-4653) ${ }^{1}$

Léo Heller (http://orcid.org/0000-0003-0175-0180) ${ }^{2}$

${ }^{1}$ Instituto Federal de Educação, Ciência e Tecnologia do Pará. Av. Almirante Barroso 1155, Marco. 66093-020 Belém PA Brasil. cezarina.souza@ifpa.edu.br

${ }^{2}$ Instituto René Rachou

(Fiocruz Minas). Belo

Horizonte MG Brasil.

\begin{abstract}
Deliberation in municipal councils of sanitation and health is the object of this study. Deliberation is understood as decision making and argumentative process, from the formulations of Rousseau, Habermas and Cohen. The proposed objective was to evaluate the effectiveness of the deliberative action of the councils of Belo Horizonte (MG) and Belém (PA). The evaluation included the study of variables defining the degree of institutionalization of the councils and revealing the dynamics of the deliberative process developed in them. The internal regulations of each council and the minutes and resolutions produced by them during the 2012-2014 triennium were consulted. The results showed that the four councils, in the period and according to the defined criteria of analysis, are far from the degree of deliberative effectiveness desired, considering the purposes of the social control in sanitation and in health, arranged by the specific legislation of each area. Even with broader experience, considering their years of participatory pedagogical exercise, health councils were no more effective than neophyte sanitation councils.
\end{abstract}

Key words Sanitation, Social Participation, Social Control, Deliberation. Health.
Resumo A deliberação em conselhos municipais de saneamento e de saúde é objeto deste estudo, entendida como processo decisionístico e argumentativo, a partir das formulações de Rousseau, Habermas e Cohen. O objetivo proposto foi avaliar a efetividade da atuação deliberativa dos conselhos de Belo Horizonte (MG) e de Belém (PA). A avaliação abrangeu o estudo de variáveis definidoras do grau de institucionalização dos conselhos e reveladoras da dinâmica do processo deliberativo neles desenvolvido. Foram consultados o Regimento Interno de cada conselho e as atas e resoluções produzidas por eles no triênio 2012-2014. Os resultados revelaram que os quatro conselhos, no periodo e segundo os critérios de análise definidos, estão distantes do grau de efetividade deliberativa desejado, tendo em vista os propósitos do controle social em saneamento e em saúde, dispostos pela legislação específica de cada área. Mesmo com experiência mais larga, considerando seus anos de exercício pedagógico e democrático de participação, os conselhos de saúde não se mostraram mais efetivos que os neófitos conselhos de saneamento. Palavras-chave Saneamento, Participação Social, Controle Social, Deliberação, Saúde. 


\section{Introdução}

Em 2007, a Lei Federal no 11.445 instituiu o controle social como um dos princípios a partir dos quais os serviços de saneamento devem ser prestados em todo o território nacional, com vistas a assegurar à sociedade acesso a informações, representações técnicas e participações nos processos de formulação de políticas, de planejamento e de avaliação a eles relacionados ${ }^{1}$.

Regulamentando essa Lei, o Decreto Federal $\mathrm{n}^{\circ} 7.217 / 2010$ previu diversos mecanismos de controle social, dentre eles os órgãos colegiados ${ }^{2}$, também existentes em outros campos de políticas públicas, desde a promulgação da Constituição Federal de 1988.

Enquanto diversos desses órgãos, nas áreas de saúde, recursos hídricos, meio ambiente, direitos da criança e do adolescente, assistência social e educação, por exemplo, foram criados tendo assegurada de forma clara sua natureza deliberativa, na área de saneamento esse fato não ocorreu. Ao contrário, o referido Decreto reporta-se à possibilidade do exercício do controle social por meio de órgãos de caráter consultivo (Artigo 34, capítulo 5$)^{2}$.

No entanto, constata-se na área a existência de instâncias deliberativas, criadas a partir de $2007^{3}$ e mesmo antes ${ }^{4}$, como por exemplo, respectivamente, o Conselho Superior da Agência Reguladora Municipal de Água e Esgoto de Belém (CSAMAE), que tem atribuições de controle social, e o Conselho Municipal de Saneamento de Belo Horizonte (COMUSA).

Considerando essa peculiaridade, é oportuno conhecer como está se dando a prática deliberativa nesses conselhos. Para tanto, e em comparação com órgãos colegiados deliberativos mais antigos - o Conselho Municipal de Saúde de Belém (CMS/Bel) e o Conselho Municipal de Saúde de Belo Horizonte (CMS/BH) -, este trabalho busca responder à questão: qual o grau de efetividade deliberativa dos quatro conselhos em estudo?

Não se trata de considerar a antiguidade como variável de avaliação da efetividade deliberativa, mas apenas como fator que propicia, em tese, o chamado exercício pedagógico e democrático de participação ${ }^{5}$, que poderá se refletir em maior efetividade. Ao comparar conselhos atentos a políticas sociais distintas, embora interconectadas, busca-se avaliar o quanto, na área de saneamento, pode a neófita instituição do controle social ser considerada efetiva. Para tanto, toma-se como parâmetro a experiência de quase três décadas de exercício da participação da comunidade na ges- tão do Sistema Único de Saúde (SUS), conforme regulamenta a Lei Federal no 8.142/19906.

Para a área da saúde, este pode ser mais um dentre inúmeros estudos já produzidos sobre o tema ${ }^{7}$, mas para a área de saneamento, é iniciativa mais relevante, pois são escassos os estudos sobre os conselhos ${ }^{8}$ e não foi identificado nenhum voltado especificamente para o tema.

As seções seguintes apresentam uma discussão conceitual sobre deliberação e efetividade deliberativa; a contextualização dos conselhos em estudo; os procedimentos metodológicos adotados; os resultados obtidos e sua discussão e as considerações finais.

\section{Deliberação e efetividade deliberativa}

Considerando que o tema central deste estudo é a deliberação, há duas questões cujo esclarecimento é fundamental para a compreensão dos seus achados: 1) qual o significado deste termo?; 2) de que forma é aqui abordado?

Para responder à primeira questão, oportuno é recorrer a um estudo que, ao se debruçar sobre as formulações de diversos autores, desde Jean Jacques Rousseau, discute a passagem, no interior da teoria democrática contemporânea, de um conceito decisionístico de deliberação, cuja base se encontra no pensamento rousseauniano, para um conceito argumentativo, consolidado por Jurgen Habermas e Joshua Cohen, a partir dos anos $1970^{9}$.

O conceito decisionístico privilegia o momento da tomada de decisão e resume-se a ele, no qual, com base na vontade da maioria, uma proposta é sagrada vencedora. O conceito argumentativo considera que a deliberação é um processo no qual um ou mais agentes avaliam as razões que permeiam uma questão, privilegiando o debate de ideias 9 .

Relativamente à segunda questão, a abordagem proposta neste estudo não se vincula aos conceitos em tela de forma excludente. Ao contrário, a deliberação, cuja efetividade se busca avaliar, está alinhada à ideia de um processo deliberativo que envolve ambos os conceitos pois, nas línguas latinas e na inglesa, considera-se que a palavra deliberação tem os dois significados etimológicos: 1) decidir, resolver; 2) ponderar, refletir? 9 .

Uma terceira questão igualmente se impõe: o que vem a ser a efetividade deliberativa? Trata-se da capacidade efetiva de os fóruns participativos atuarem sobre a política pública, de modo a influenciá-la, controlá-la e defini-la. Nesse sentido, 
ela se expressa e pode ser analisada com base em elementos externos e intrínsecos aos conselhos ${ }^{10}$.

No rol de fatores externos estão: as coalizões de governo formadas pelos partidos políticos, que podem ou não sustentar a delegação de poder aos cidadãos; a experiência associativa das comunidades; a conjunção de forças sociais e políticas interessadas nas experiências participativas ${ }^{10}$.

Dentre os fatores internos está o desenho institucional: paridade entre os membros do conselho, não apenas em termos de igualdade numérica, mas também quanto às condições de acesso a informações e à possibilidade de formação e disponibilidade de tempo dos conselheiros; representatividade desses membros, traduzida como sendo sua autoridade para falar em nome do segmento que representam e não em nome pessoal ${ }^{11}$; presença de grupos fortes para influenciar decisões ${ }^{10}$. A existência de comissões e câmaras técnicas que funcionem como canais de acesso a informações por parte dos conselheiros, assim como a forma de escolha do presidente do conselho igualmente são destacadas como fatores concorrentes para a efetividade deliberativa ${ }^{12}$.

No plano nacional, há relatos de investigações conduzidas no Paraná, Goiás, Mato Grosso do Sul e diversos Estados nordestinos, que identificaram baixa capacidade deliberativa nas instâncias estudadas. São apontadas como motivações para tal fato: 1) a centralidade do Poder Executivo na definição dos assuntos relevantes para discussão nos conselhos; 2) a ausência de debate, inclusive em se tratando de temas voltados para as políticas públicas, o que evidencia um certo "consenso" ou "harmonia", que não se coadunam com as expectativas da deliberação democrática, marcada pela explicitação dos conflitos; 3) a falta de capacitação dos conselheiros, inclusive para conhecer a conjuntura financeira em que se encontra a política a que se vinculam; 4) a baixa representatividade; 5) a dificuldade em lidar com a pluralidade de interesses; 6) a manutenção de padrões clientelistas entre Estado e sociedade; 7) a recusa do Estado em compartilhar o poder; 8) a burocratização e a restrição à participação direta dos cidadãos; 9) a não realização de reuniões; 10) a ausência de paridade, dentre outras ${ }^{5,13,14}$.

Uma pesquisa realizada no município de Guarulhos (SP), que analisou atos administrativos de diversos conselhos locais, revela que a atividade deliberativa se mostra mais elevada naqueles que recebem alta indução federal (com destaque para o repasse condicionado de recursos), que estão amplamente difundidos no País e bem integrados a seus respectivos setores ou áreas de políticas ${ }^{7}$. Mesmo em se tratando de um conselho de caráter deliberativo para fins de auto-regulamentação e apenas consultivo para os demais fins, como é o caso do Conselho das Cidades (ConCidades), esse patamar de efetividade também foi vivenciado entre 2003 e 2005, no qual, independentemente das limitações impostas por esse desenho institucional, por conta da vontade e do comprometimento político vigentes, o conselho exerceu influência nos processos decisórios do Ministério das Cidades e de outros órgãos para os quais encaminhou resoluções, dentre eles, inclusive, o Congresso Nacional ${ }^{15}$.

No plano internacional, igualmente há referências à baixa influência das instâncias participativas sobre a política pública. Esse é o caso, por exemplo, do Reino Unido, onde atuaram os community health concils ${ }^{16}$. Há relatos de que o papel desses fóruns em influenciar decisões e determinar prioridades foi menos efetivo do que sugere a retórica oficial que os sustentou ${ }^{17,18}$. Da mesma forma, na Espanha e em Portugal, como também na Itália e Grécia, o discurso político não tem redundado em experiências práticas capazes de tornar efetiva a participação dos usuários dos serviços $^{19,20}$.

Por outro lado, uma pesquisa conduzida no México, indica que o chamado aval ciudadano (estratégia institucional de vigilância da qualidade dos serviços de saúde) tem grande potencial para representar os usuários e influenciar a prestação dos serviços ${ }^{21}$. Na Colômbia, onde atuam um Comitê de Participação Comunitária e associações de usuários, um estudo argumenta que, apesar de seus achados apontarem para a satisfação de seus entrevistados quanto a sua capacidade de influenciar a condução dos serviços de saúde, nem sempre há espaços e respostas institucionais efetivas ${ }^{22}$.

\section{Contextualização dos conselhos em estudo}

O COMUSA foi criado e iniciou suas atividades antes da promulgação da Lei no 11.445/2007, diferentemente do CSAMAE, cuja criação ocorreu um ano depois dessa legislação, tendo se passado mais sete anos até o início de sua atuação.

O CMS/Bel foi criado alguns meses antes das leis infraconstitucionais regulamentadoras do SUS (não foi informado pelo CMS/Bel o ano em que o conselho entrou em funcionamento), enquanto que a criação e o início das atividades do $\mathrm{CMS} / \mathrm{BH}$ são posteriores a essas leis.

Os quatro conselhos têm caráter deliberativo. Merece destaque este fato, considerando-se 
que, seis anos antes da legislação que determina a criação de conselhos de saneamento de caráter consultivo, o COMUSA foi criado já assumindo aquela natureza.

Sobre o COMUSA, um único estudo foi encontrado $^{23}$. Sua conclusão destaca que, embora com méritos (trouxe e poderá trazer ainda mais modificações positivas para o cenário do saneamento em Belo Horizonte), entre 2004 e 2008, o conselho não estava sendo capaz de garantir o controle social. Havia limitações quanto à geração de propostas próprias e atuação sobre a política pública, com a sensação de que as definições aprovadas não passavam de propostas prontas que a Prefeitura de Belo Horizonte $(\mathrm{PBH})$ levaria a cabo mesmo que o conselho não existisse.

Sobre o CMS/BH citam-se diversos traba$\operatorname{lhos}^{24-28}$. Um deles destaca duas possibilidades ${ }^{28}$ : 1) os prefeitos (entre 1997 e 2008) não estarem assumindo publicamente seus vetos, pois, ao não homologar as resoluções aprovadas pelo Conselho e que não estavam alinhadas com seus interesses, estariam buscando evitar o ônus político que significaria vetá-las; 2) o CMS/BH, no período acima citado, ao não acionar o Ministério Público contra a $\mathrm{PBH}$ pela não homologação das resoluções aprovadas, estaria ainda vivenciando limitações quanto ao exercício de seu poder, por conta de aspectos históricos da sociedade brasileira ou de vinculações político-partidárias com o Executivo.

Não foram encontrados estudos sobre o CSAMAE e, sobre o CMS/Bel, foi identificado apenas um trabalho ${ }^{29}$. Nele, a autora aponta características que marcavam o conselho entre 2010 e 2011, como por exemplo, a insegurança dos conselheiros diante do poder que exercem e da responsabilidade consequente.

\section{Procedimentos metodológicos}

Este é um estudo descritivo ${ }^{30}$, baseado em análise documental ${ }^{31}$, que adotou, com adaptações, variáveis de análise propostas em outros estudos ${ }^{32}$. Também foram realizadas observações durante as plenárias dos conselhos e, em caso pontual, houve diálogo informal com presidente de conselho de saúde.

Foram definidos dois grupos de variáveis: 1) definidoras do grau de institucionalização dos conselhos; 2) reveladoras da dinâmica do processo deliberativo desenvolvido nessas instâncias.

As variáveis do primeiro grupo (órgãos internos; frequência e local das reuniões ordinárias segundo o Regimento Interno - RI; número de membros e paridade; escolha dos membros; escolha da presidência; mandato e reeleição; proposição da pauta; tomada de decisões; formalidade para publicização das decisões) possibilitam avaliar a estrutura organizativa dos conselhos, sua composição e os procedimentos adotados para seu funcionamento, considerando que seu formato ou desenho institucional influencia sua efetividade deliberativa ${ }^{12}$.

Tais variáveis foram estudadas por meio de análise documental. Foi objeto dessa análise o RI dos conselhos (vigente durante o período de interesse da pesquisa) por ser ele documento capaz de revelar as condições normativas que podem ou não favorecer um processo democrático e inclusivo nesses órgãos.

Relativamente ao período de interesse da pesquisa, buscou-se analisar um intervalo temporal recente, que oportunizasse o estudo em duas gestões municipais consecutivas, com e sem a troca de prefeitos. Assim, foi definido o triênio de 2012 a 2014, uma vez que, no caso de Belém, 2012 correspondeu ao final de uma gestão e 2013 e 2014 aos dois primeiros anos da gestão de um novo prefeito. Em Belo Horizonte, como ocorreu a reeleição do prefeito em 2012, têm-se duas gestões do mesmo prefeito. Além disso, considerando que o início da atuação do CSAMAE se deu em 2015, definiu-se esse como o ano de interesse para esse conselho.

Assim, foram consultados: RI COMUSA aprovado pelo Decreto no 11.730/2004 e alterado pela Lei no 10.433/2012; RI CMS/BH aprovado em 2007 e substituído conforme a Resolução no 366/2014; RI CSAMAE aprovado pela Resolução no 002/2015; RI CMS/Bel aprovado em 2001.

No segundo grupo estão as variáveis: igualdade deliberativa; decisões prevalentes; funções prevalentes; número de resoluções publicadas e não publicadas. A variável igualdade deliberativa fundamenta-se na ideia de possibilidade igual, para todos os sujeitos do processo, de apresentação de temas à agenda e de razões ao debate ${ }^{10}$. Visa a avaliar a capacidade de verbalização e de influência de cada um dos segmentos que compõem o conselho nas decisões tomadas. Expressa-se pelo número de vocalizações, ou seja, de manifestações ocorridas durante as reuniões e pela ocorrência da proposição de temas para debate durante as sessões, a serem incluídos ou não na pauta pelo seu definidor/organizador.

A variável decisões prevalentes revela o teor das decisões tomadas pelos conselhos, o que indica as funções prevalentes que estão sendo exercidas, as- 
sim categorizadas: proposição de políticas; controle de políticas; outras funções. A primeira delas está ligada aos aspectos mais centrais da política à qual o conselho se vincula, compreendendo, por exemplo, a proposição de orçamento e de planos de ação, a apreciação de relatórios de gestão.

A função de controle contempla o acompanhamento e a avaliação das ações do Estado, expressando-se por meio de denúncias, propostas de intervenção e avaliação dos serviços prestados. As demais funções exercidas pelos conselhos, categorizadas como outras, correspondem à organização interna, informes, problemas não relacionados à política propriamente dita.

$\mathrm{O}$ número de resoluções publicadas e não publicadas no Diário Oficial do Município (DOM) é uma variável que indica a possibilidade de tensão existente entre o conselho e o Executivo, considerando a variável formalidade para publicização das deliberações, pertencente ao primeiro grupo de variáveis em estudo, e o que sinaliza a literatura ${ }^{28}$.

Para o estudo dessas variáveis foram analisadas as atas e resoluções aprovadas pelos conselhos nos anos de interesse da pesquisa, destacando-se que o CMS/Bel não disponibilizou as atas de 2012 e 2013.

Após o estudo dessas variáveis, para cada conselho, foi avaliado seu grau de efetividade, adotando-se quatro dimensões avaliativas. Para cada uma foram definidos três diferentes graus de efetividade, conforme apresentado no Quadro 1.

\section{Resultados e discussão}

\section{Grau de institucionalização dos conselhos}

Relativamente aos órgãos internos, verifica-se que, de maneira geral, o desenho dos conselhos de saúde, entre si, é semelhante, o mesmo acontecendo com os de saneamento.

Os conselhos de saneamento dispõem de número menor de órgãos, não apresentando comissões e câmaras técnicas. Tal fato poderia comprometer suas ações, uma vez que esses órgãos contribuem para o esclarecimento dos conselheiros acerca de temas específicos que, muitas vezes, desconhecem ${ }^{12}$. Entretanto, esses conselhos são essencialmente técnicos. Mesmo com formações acadêmicas diferentes, os conselheiros "se bastam a si mesmos", o que não aconteceria se o perfil dos conselhos fosse mais ampliado, incluindo uma representação popular, como no caso dos conselhos de saúde.

Em que pese não ter designado em seu RI a existência de uma Secretaria, o COMUSA dispõe desse órgão, tanto quanto o CSAMAE, haja vista que as atas das reuniões são por ele elaboradas. Da mesma forma, embora não tenha explicitado a existência de assessorias, como o fez o CMS/Bel, que conta com uma Assessoria Técnica, o CMS/ BH dispõe de uma, de natureza contábil. Além disso, mesmo com nomes diferentes, as câmaras do CMS/BH e as comissões e câmaras específicas do CMS/Bel exercem funções semelhantes.

Quadro 1. Graus de efetividade deliberativa.

\begin{tabular}{|c|c|c|c|}
\hline Dimensão & Alto & Médio & Baixo \\
\hline $\begin{array}{l}\text { Igualdade } \\
\text { deliberativa }\end{array}$ & $\begin{array}{l}\text { Predominância de } \\
\text { usuários/sociedade } \\
\text { civil na vocalização e } \\
\text { proposição de temas. }\end{array}$ & $\begin{array}{l}\text { Predominância de } \\
\text { trabalhadores/prestadores* } \\
\text { na vocalização e } \\
\text { proposição de agenda. }\end{array}$ & $\begin{array}{l}\text { Predominância de gestores/ poder } \\
\text { público na vocalização e proposição } \\
\text { de temas. }\end{array}$ \\
\hline $\begin{array}{l}\text { Tipo de decisão } \\
\text { tomada }\end{array}$ & $\begin{array}{l}\text { Interferência na } \\
\text { elaboração da política } \\
\text { pública. }\end{array}$ & $\begin{array}{l}\text { Controle das ações } \\
\text { públicas. }\end{array}$ & Questões de menor relevância. \\
\hline Função exercida & $\begin{array}{l}\text { Prevalência de } \\
\text { funções propositivas. }\end{array}$ & $\begin{array}{l}\text { Prevalência de funções de } \\
\text { controle. }\end{array}$ & Prevalência de outras funções. \\
\hline $\begin{array}{l}\text { Publicização de } \\
\text { decisões }\end{array}$ & \begin{tabular}{|l|} 
Decisões não \\
requererem \\
homologação do \\
Executivo; todas \\
são publicadas; o \\
presidente é eleito \\
entre os conselheiros.
\end{tabular} & 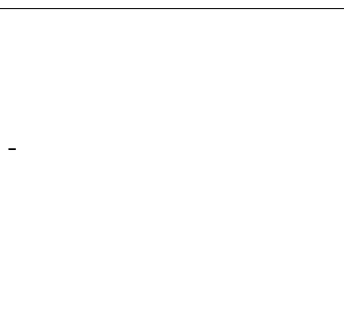 & $\begin{array}{l}\text { Decisões requererem homologação } \\
\text { do Executivo; pelo menos uma não } \\
\text { publicada; presidente eleito entre os } \\
\text { conselheiros. } \\
\text { Decisões não requererem } \\
\text { homologação do Executivo; pelo } \\
\text { menos uma não publicada; presidente } \\
\text { membro do Executivo. }\end{array}$ \\
\hline
\end{tabular}

${ }^{*}$ Aplica-se somente aos conselhos de saúde. 
Além das semelhanças apontadas, há diferenças. O CMS/Bel não criou, como o fez o CMS/ $\mathrm{BH}$, plenárias setoriais (plenárias dos movimentos de mulheres, de aposentados, de comunidades, de sindicatos do setor produtivo, de portadores de patologias crônicas, de trabalhadores da saúde, de gestores e prestadores dos serviços).

Diferentemente do CSAMAE, de modo a promover (não a incluir) a participação popular, o COMUSA dispõe de uma comissão constituída por 32 representantes de movimentos sociais, criada em 2009, por ocasião da II Conferência Municipal de Saneamento, com o fim de acompanhar as reuniões do conselho. Seus membros não detêm direito de voto; apenas de voz.

É significativa a diferença quanto à frequência de realização das reuniões ordinárias entre o CSAMAE (duas vezes por semestre) e os demais conselhos (mensalmente). Em que pese o intervalo maior definido entre elas, não há registros de que não tenham ocorrido, ao contrário do CMS/Bel, em que este fato se deu mais de uma vez, o que é apontado pela literatura como um fator comprometedor da capacidade deliberativa ${ }^{5}$.

Por outro lado, nenhum deles define, em seu RI, o local de realização das mesmas. Tomando como referência as 95 atas consultadas, enquanto os demais utilizam outros espaços cedidos pela Prefeitura, o CMS/Bel informa reunir em sala própria. Contudo, pelo observado em visita in loco, trata-se de local pequeno e abafado. Por isso, o conselho costuma limitar o número de visitantes que queiram assistir as reuniões, já tendo cancelado algumas delas, como já mencionado, em função de panes no equipamento de refrigeração lá instalado.

Observa-se, também, que o COMUSA, o CSAMAE e o CMS/Bel possuem um número próximo de conselheiros, abaixo, porém, do número fixado para o $\mathrm{CMS} / \mathrm{BH}$. Nos conselhos de saúde, segundo seu RI, o segmento usuário contempla entidades do movimento de mulheres, de portadores de deficiências e patologias, de moradores, do movimento sindical do setor produtivo e de serviços, além, no caso do CMS/ $\mathrm{BH}$, das regionais de saúde do município. Já nos conselhos de saneamento, a participação popular é mais restrita.

Nesses conselhos, no segmento sociedade civil há apenas um representante de associação de bairro ou de moradores (a comissão popular do COMUSA não integra o conselho propriamente dito). Os demais são oriundos de entidades patronais, sindicais de trabalhadores, fiscalizadoras do exercício das profissões de engenharia e ad- vocacia, assim como organizações não governamentais com atuação na área de saneamento e ambiente. Especificamente no COMUSA, incluem também esse segmento representantes de universidade, conselho de saúde, um cientista, tecnólogo, pesquisador ou indivíduo de notório saber, dedicado a atividades correlatas.

No que se refere à paridade, tal característica é encontrada nos conselhos de saúde, em formato tripartite, assegurando maior representação de usuários frente aos demais segmentos. Nos conselhos de saneamento, há a paridade numérica entre representantes do Poder Público e da sociedade civil, mas, como neste último segmento é limitada a representação do simples usuário dos serviços de saneamento, de uma certa maneira, a paridade - fator relevante para a efetividade deliberativa $^{5}$ - fica prejudicada.

Em todos os conselhos estudados os membros são escolhidos e indicados no âmbito do segmento que representam, sem interferência externa, dentro do que se considera como sendo um padrão comum de escolha das representações, embora haja exceções, inclusive na área de saúde ${ }^{12}$.

Apesar de suas tradições democráticas, há relatos sobre conselhos de saúde dos quais o secretário da pasta é o presidente nato ${ }^{14}$. Este não é o caso do CMS/Bel e do CMS/BH, que já avançaram para um processo que, em tese, enseja alguma distribuição de poder e a não preponderância do Executivo sobre os demais segmentos. Mas, é o que ocorre nos conselhos de saneamento, apenas substituindo a figura do secretário pela do representante do Prefeito, no caso do COMUSA, e pela do diretor presidente da Agência Reguladora Municipal de Âgua e Esgoto de Belém (AMAE), no caso do CSAMAE. Fatos como esses, por mais acessível e democrática que seja a postura do presidente, não descaracterizam o monopólio do cargo por representante do Executivo ${ }^{12}$.

No que concerne aos mandatos, estes são fixados em dois anos para todos os conselheiros, inclusive para o presidente dos conselhos. Somente no caso do CSAMAE, como o presidente é o próprio diretor presidente da agência, o mandato é de quatro anos.

Diferentemente dos demais, o RI do CMS/Bel não menciona a possibilidade de reeleição dos representantes dos usuários, prestadores privados $\mathrm{e}$ trabalhadores e nem de recondução de representantes do Poder Público. Entretanto, referências a ambas foram observadas no texto das resoluções e confirmadas em meio a diálogo informal com seu atual presidente.

A baixa renovação de um conselho com a não 
assunção de novos conselheiros e presidentes é considerada vantajosa (aquisição de familiaridade com os temas tratados) e desvantajosa (profissionalização e afastamento do conselheiro de sua base ${ }^{26}$. No presente caso, constata-se, nos conselhos de saúde e no COMUSA, relativa renovação.

Os conselhos adotam procedimentos diferenciados para definir suas pautas. O COMUSA e o CSAMAE excluem o plenário dessa função, mantendo-a como prerrogativa exclusiva do Executivo, aproximando-se do que descreve a literatura ao se referir à centralidade desse Poder na definição dos assuntos que devem ser objeto de análise pelo conselho ${ }^{13}$. O CMS/Bel privilegia o plenário. Contudo, durante a leitura das atas, não foram identificados relatos a respeito.

Nenhum dos RI consultados informa se as deliberações ordinárias se darão por voto aberto ou secreto, mas, por conta de observação feita in loco durante reuniões plenárias do COMUSA, do CMS/BH e do CSAMAE, os votos foram manifestados de forma aberta. No RI deste último há, contudo, previsão especial de voto secreto quando se tratar da destituição de algum conselheiro. Quanto ao CMS/Bel, não houve possibilidade de observação por conta do cancelamento de reuniões, conforme já mencionado.

Em todos os casos as decisões são tomadas por maioria simples de votos, exigindo-se maioria qualificada apenas para alterar o RI. Destacase o fato de os conselhos de saneamento assegurarem a seu presidente o voto de qualidade. Isto, em si mesmo, já fere os princípios democráticos, mas, levando em conta que o cargo de presidente nesses conselhos é, de forma regimental, exercido por representante do Executivo, tem-se comprometimento ainda maior da qualidade do exercício democrático pretendido ${ }^{23}$.

Os conselhos de saneamento têm a prerrogativa de encaminhar suas deliberações para publicação no DOM sem a obrigatoriedade de homologação prévia pelo Executivo, diferentemente de como se dá com os conselhos de saúde. Relacionando este fato com a variável escolha da presidência, observa-se que há uma espécie de "compensação" promovida pelo Executivo, com o fim de assegurar seu controle sobre os conselhos. Como os conselhos de saneamento são presididos por representante nato do Executivo, têm autonomia para publicizar suas deliberações. Já os conselhos de saúde, cujo presidente pode ser um representante de outros segmentos, obrigatoriamente têm que submeter previamente suas deliberações à homologação do secretário da pasta ou do próprio prefeito para que, posteriormente, sejam publicadas. Em ambos os casos, isto, sem dúvida, pode representar uma restrição à capacidade deliberativa desses conselhos ${ }^{28}$.

\section{Dinâmica do processo deliberativo nos conselhos}

A avaliação da variável igualdade deliberativa, que abrange a vocalização nos debates e a proposição de temas, foi prejudicada em relação ao COMUSA por conta do laconismo das atas desse conselho. Em sua quase totalidade, apenas referem à ocorrência de debates sobre os pontos de pauta $\mathrm{e}$ pouco citam os nomes dos conselheiros que se manifestaram e o teor de suas falas. Assim, tornou-se inviável analisar esse conselho relativamente a essa variável. Isto prejudica o estudo proposto, mas reforça a análise feita em outro estudo ${ }^{23}$, que também destacou essa limitação do referido conselho. Além disso, sugere a possibilidade de que nele a ata esteja sendo tomada por mero requisito a ser cumprido em atenção a exigências legais ${ }^{10}$.

No CMS/BH, em cada um dos anos, o número de vocalizações do segmento gestores/prestadores/formadores foi o menor em comparação com o dos demais segmentos. No total, os trabalhadores produziram o maior número de vocalizações e o mesmo número de proposições de temas que os usuários, revelando que, nesse período, embora tenha sido intensa a participação propositiva destes, foram aqueles que se mantiveram com maior poder de influência no conselho. Esse achado é interessante, por revelar a força desse segmento e diferir de outros que indicam a preponderância do Executivo ${ }^{10}$.

No CSAMAE, sociedade civil e Poder Público se igualaram em número de vocalizações e não houve proposição de tema durante as reuniões ocorridas no ano em estudo. Contudo, levando em conta que a pauta é organizada pela Secretaria do conselho, ligada ao Executivo, e que a representação da sociedade civil inclui apenas uma entidade do movimento popular, ausente nas duas reuniões havidas no período, pode-se considerar que o maior poder de influência sobre o conselho não está nas mãos dos usuários dos serviços de saneamento adstritos ao conselho.

No CMS/Bel pode-se observar que a influência do segmento usuário prevaleceu sobre os demais, tanto em número de vocalizações, quanto em número de proposições de temas para discussão, também diferindo do citado na literatura consultada ${ }^{10}$. Esse achado, contudo, e todos os demais resultantes da análise das atas desse Conselho, fica comprometido, uma vez que não 
foram por ele disponibilizadas as atas dos anos 2012 e 2013. Isto, se por um lado prejudica a análise da variável igualdade deliberativa, por outro favorece a investigação do grau de institucionalização do conselho, depondo contra sua capacidade de organização e de franquear livre acesso do cidadão a seus registros ${ }^{10}$.

Quanto às decisões prevalentes, é bastante variado seu leque de temáticas, que vão desde a aprovação da política municipal, passando pela gestão dos recursos financeiros e a definição de tarifas, até a aprovação de atas, nomes de conselheiros para representar o conselho, calendários de reuniões e chamamentos públicos.

Destaca-se a produção do $\mathrm{CMS} / \mathrm{BH}$ que, ao longo do triênio de interesse da pesquisa, tomou 150 decisões, enquanto que o COMUSA, apenas 12. Entretanto, é relevante observar, nessa comparação, o tipo de decisão prevalente. Do total de decisões do $\mathrm{CMS} / \mathrm{BH}, 56 \%(\mathrm{n}=85)$ estão relacionadas a assuntos internos do conselho. Já no caso do COMUSA, $66 \%(\mathrm{n}=8)$ delas interferem diretamente na política pública. Contudo, como neste conselho não foi possível avaliar de forma mais detalhada as vocalizações ocorridas nos debates, fica em aberto uma pergunta, que se pode propor tendo em mente relatos de decisões tomadas na ausência de debates, conduzidas exclusivamente pelo Executivo, com incidência direta sobre a política pública ${ }^{13}$ : qual o grau de influência do Executivo nessas decisões do COMUSA?

$\mathrm{Na}$ ordem de prevalência, o COMUSA exerceu, no triênio considerado, a função que se pode chamar de "função de escuta", ligada ao recebimento de informações fornecidas pela PBH e outros órgãos sobre ações e projetos (15 ocorrências). Em segundo lugar, apareceu a função propositiva em relação à política pública, que corresponde à maior capacidade de influência sobre as ações do Estado ${ }^{10}$.

No CMS/BH, de 2012 a 2014, e no CSAMAE, em 2015, prevaleceu a função ligada à organização interna, vindo em segundo lugar, respectivamente, a função de controle das ações públicas e a função propositiva. O CMS/BH ainda exerceu, em um terceiro grau de prevalência, a função propositiva. O CMS/Bel, em 2014, atuou prevalentemente na função de controle, seguida da função propositiva e da função de organização interna, o que indica atenuação da burocracia, obstáculos e falta de estrutura que o caracterizavam em anos anteriores ${ }^{29}$.

Os conselhos de saneamento publicaram todas as resoluções que aprovaram no período, o mesmo, entretanto, não acontecendo com os de saúde, o que pode estar relacionado com o cerceamento intencional da capacidade de deliberação dos conselhos por parte do Executivo e sua dificuldade de compartilhar o poder ${ }^{13,28}$.

De um total de 64 resoluções do CMS/BH, $28 \%(\mathrm{n}=18)$ não foram homologadas pelo Executivo para publicação. No CMS/Bel, duas resoluções aprovadas pelo pleno não foram publicadas e sete, que haviam sido aprovadas pela mesa diretora ad referendum, também não o foram, ocorrendo sua revogação pouco tempo depois. Além disso, há outras 17 resoluções também não publicadas, mas cuja existência é duvidosa, pois como o Conselho não entregou suas cópias impressas, paira a suspeita de que pode ter havido falha na numeração e nunca terem, de fato, existido. Assim, levando em conta essas circunstâncias, considera-se que apenas duas resoluções aprovadas não foram publicadas, o que equivale a pouco mais de $1 \%$ do total de 171 resoluções. Os temas por elas abordados foram a instalação do Centro de Especialidades Médicas e Odontológicas, a revogação de uma das resoluções aprovadas ad referendum e encaminhamento do Plano Municipal de Saúde para a Comissão Científica do conselho.

Estes fatos, que por si já se revestem de gravidade, tornam-se mais relevantes ainda considerando-se que os conselhos não recorreram ao Ministério Público pleiteando as homologações, tal como relatam outros estudos ${ }^{28}$.

\section{Grau de efetividade deliberativa}

Para os quatros conselhos, o Quadro 2 apresenta o grau de efetividade deliberativa. Não foi possível determina-lo para o COMUSA em relação à dimensão igualdade deliberativa, uma vez que as variáveis que a definem mostraram-se contraditórias: na vocalização prevalece a sociedade civil; na proposição de temas, o Poder Público.

Aliás, o conjunto de dimensões, no caso do COMUSA, revela um paradoxo, pois, embora tenha alta efetividade quanto ao tipo de decisão tomada (incidem sobre a política), não alcança o mesmo desempenho quanto à função exercida (função de "escuta") e à publicização de decisões (deliberações publicadas sem homologação do Executivo porque são aprovadas por seu representante, que preside o conselho).

No CMS/BH, é baixo o grau de efetividade nas dimensões tipo de decisão tomada (ligadas a questões internas do conselho), função exercida (ligada a questões internas do conselho) e publicização de decisões (publicadas somente após 
Quadro 2. Grau de efetividade deliberativa dos conselhos estudados.

\begin{tabular}{|l|c|c|c|c|}
\hline \multicolumn{1}{|c|}{ Dimensões } & Comusa & CMS/BH & CSAMAE & CMS/Bel \\
\hline Igualdade deliberativa & Indefinido & Médio & Baixo & Alto \\
\hline Tipo de decisão tomada & Alto & Baixo & Baixo & Médio \\
\hline Função exercida & Baixo & Baixo & Baixo & Médio \\
\hline $\begin{array}{l}\text { Publicização de decisões (formalidade, escolha da } \\
\text { presidência e número de resoluções não publicadas) }\end{array}$ & Baixo & Baixo & Baixo & Baixo \\
\hline
\end{tabular}

homologação do Executivo, com algumas não publicadas, sendo o presidente de fora do Executivo). Foi avaliada como média a efetividade quanto à igualdade deliberativa (prevalecem vocalizações de trabalhadores e, numericamente empatadas, proposições de temas de usuários e trabalhadores).

Em todas as dimensões foi avaliada como baixa a efetividade deliberativa do CSAMAE. Quanto à igualdade deliberativa, prevalecem, com o mesmo número de ocorrências, as vocalizações da sociedade civil e do Poder Público, sem proposição de temas. O tipo de decisão tomada e a função exercida incidem sobre a organização interna do Conselho e, quanto à publicização de decisões, todas foram publicadas sem homologação pelo Executivo, uma vez que são aprovadas por seu representante, que preside o conselho.

O CMS/Bel foi o conselho que apresentou maior variabilidade quanto à efetividade. A igualdade deliberativa foi considerada alta (prevalecem as vocalizações e a proposição de temas por usuários), médios o tipo de decisão tomada (ligadas ao controle das ações públicas) e a função exercida (função de controle) e baixa a publicização de decisões (publicadas somente após homologação do Executivo, com algumas não publicadas, sendo o presidente de fora do Executivo).

\section{Considerações finais}

Os quatro conselhos estudados, no período e segundo os critérios de análise definidos, estão distantes do grau de efetividade deliberativa desejado, tendo em vista os propósitos do controle social em saneamento e em saúde, dispostos pela legislação específica de cada área. Mesmo com experiência mais larga, considerando seus anos de exercício pedagógico e democrático de participação, os conselhos de saúde não se mostraram mais efetivos que os neófitos conselhos de saneamento.

Isto é um fato que, contudo, não deve ser interpretado como desalentador ou indicativo de que o controle social é uma utopia, inclusive quando é deliberativa, e não apenas consultiva, a natureza dos conselhos. Admitir e reconhecer o avanço que constitui a existência de conselhos de saneamento é algo que não se pode deixar de fazer. Além disso, os limites aqui identificados são passíveis de superação no sentido de que haja predominância de usuários/sociedade civil na vocalização e proposição de temas; interferência do conselho na elaboração da política pública; prevalência de funções propositivas; resoluções que não requeiram homologação do Executivo para publicação; escolha do presidente entre os conselheiros pertencentes a todos os segmentos.

Se a busca pela efetividade nos conselhos se impõe em um contexto geral, ela é ainda mais necessária em momento histórico tão crítico como o atual, em que as ações do governo central se voltam para o congelamento dos investimentos públicos e a privatização dos serviços, o que inclui os de saneamento e os de saúde. De forma intensa, portanto, há que se firmar posição em defesa do saneamento e da saúde com controle social efetivo sobre a política estatal, que deve estar voltada para assegurar tais direitos humanos e não banalizá-los ou transformá-los em mercadorias.

\section{Colaboradores}

CMN Souza participou da coleta, análise e interpretação dos dados, revisão da literatura, concepção e redação do artigo; L Heller atuou na concepção, revisão crítica e aprovação da versão final do artigo para submissão. 


\section{Referências}

1. Brasil. Lei no 11.445 de 5 de Janeiro de 2007. Estabelece diretrizes nacionais para o saneamento básico. Diário Oficial da União; 2007.

2. Brasil. Decreto $n^{\circ} 7.217$ de 21 de Junho de 2010. Regulamente a Lei no 11.445, de 5 de janeiro de 2007, que estabelece diretrizes nacionais para o saneamento básico, e dá outras providências. Diário Oficial da União; 2010.

3. Belém. Lei no 8.630 de 7 de Fevereiro de 2008. Transforma o Serviço Autônomo de Água e Esgoto de Belém em Agência Reguladora Municipal de Água e Esgoto de Belém. Diário Oficial da União; 2008.

4. Belo Horizonte. Lei no 8.260 de 3 de Dezembro de 2001. Institui a Política Municipal de Saneamento e dá outras providências. Diário Oficial da União; 2001.

5. Silva ALN, Souza DE. Deliberação e controle social: um perfil dos conselhos estaduais de políticas públicas no nordeste brasileiro. Rev Eletr de Ciên Pol 2013;4(1-2):80-100.

6. Brasil. Lei no 8.142 de 28 de Dezembro de 1990. Dispõe sobre a participação da comunidade na gestão do SUS e sobre as transferências intergovernamentais de recursos financeiros na área da saúde. Diário Oficial da União; 1990.

7. Lavalle AG, Voigt J, Serafim L. O que fazem os conselhos e quando o fazem? Padrões decisórios e o debate dos efeitos das instituições participativas. Rev Ciên Soc 2016;59(3):609-650.

8. Piterman A. (A falta de) controle social das políticas municipais de saneamento: um estudo em quatro municípios de Minas Gerais. Saude Soc 2013;22(4):11801192.

9. Avritzer L. Teoria democrática e deliberação pública. Lua Nova 2000;49:25-46.

10. Cunha ESM. A efetividade deliberativa dos conselhos municipais de saúde e da criança e do adolescente no nordeste. In: Avritzer, L, organizador. A participação social no Nordeste. Belo Horizonte: Editora UFMG; 2007. p. 135-162.

11. Teixeira EC. Efetividade e eficácia dos conselhos. In: Carvalho MCAA, Teixeira ACC, organizadoras. Conselhos gestores de políticas públicas. São Paulo: Pólis; 2000. p. $92-96$

12. Faria CF. Sobre os determinantes das políticas participativas: a estrutura normativa e o desenho institucional dos conselhos municipais de saúde e de direitos da criança e do adolescente no nordeste. In: Avritzer, L, organizador. A participação social no Nordeste. Belo Horizonte: Editora UFMG; 2007. p. 135-162.

13. Tatagiba L. Conselhos gestores de políticas públicas e democracia participativa: aprofundando o debate. Rev Sociol Polit 2005;25:209-213.

14. van Stralen CJ, Lima AMD, Fonseca Sobrinho D, Saraiva LES, van Stralen TBS, Belisário SA. Conselhos de saúde: efetividade do controle social em municípios de Goiás e Mato Grosso do Sul. Ciên Saude Colet 2006;11(3):621-632.

15. Brasil FPD, Carneiro R, Barbosa TP, Almeida ME. Participação, desenho institucional e alcances democráticos: uma análise do Conselho das Cidades (Concidades). Rev Sociol Polí 2013;21(48):5-18.

16. Serapioni M, Romaní O. Potencialidades e desafios da participação em instâncias colegiadas dos sistemas de saúde: os casos de Itália, Inglaterra e Brasil. Cad Saude Pub 2006;22(11):2411-2421.
17. Milewa T, Valentine J, Calnan N. Managerialism and active citizenship in britain's reformed health service: power and community in an era of decentralization. Soc Scien Medic 1998;47(4):507-517.

18. Rhodes P, Nocon A. User involvement and the NHS reforms. Health Expectations 1998;1(2):73-81.

19. Matos AR, Serapioni M. O desafio da participação cidadã nos sistemas de saúde do Sul da Europa: uma revisão da literatura. Cad Saude Pub 2017;33(1):1-11.

20. Serapioni M, Duxbury N. Citizens participation in the italian health-care system: the experience of the Mixed Advisory Committees. Health Expectations 2012;17(4):488-499.

21. Nigenda-Lopez GH, Juárez-Ramiréz C. Ruíz-Larios JA, Herrera CM. Participación social y calidad de salud: la experiência del aval ciudadano em los servicios en México. Rev Saude Pub 2013;47(1):44-51.

22. Delgado-Gallego ME, Vazquez ML. Percepciones de usuarios y líderes comunitarios sobre su capacidad para influenciar em la calidad de los servicios de salud: un estudio de casos de Colombia y Brasil. Cad Saude Pub 2009;25(1):169-178.

23. Mello MCC, Rezende S. O Conselho Municipal de Saneamento de Belo Horizonte: desafios e possibilidades. Eng Sanit Ambient 2014;19(4):479-488.

24. Takamatsu SL. Gestão pública participativa: a experiência do Conselho Municipal de Saúde de Belo Horizonte [dissertação]. Rio de Janeiro: Fundação Getúlio Vargas/EBAP; 1996. [acessado 2017 Mar 08]. Disponível em: http://bibliotecadigital.fgv.br/dspace/ bitstream/handle/10438/8857/000076675.pdf?sequence $=1$ \&isAllowed $=y$

25. Bicalho MS. Conselheiros de saúde construindo o controle social do SUS. Psicol Rev 2003;10(14):149154.

26. Santos SF, Vargas AMD, Lucas SD. Conselheiros Usuários do Conselho Municipal de Saúde de Belo Horizonte: características sociais e representatividade. Saúde e Soc 2011; 20:483-495.

27. Oliveira AMC, Ianni AMZ, Dallari SG. Controle social no SUS: discurso, ação e reação. Ciên Saude Colet 2013;18(8):2329-2338.

28. Machado JA, Lucas SD. Análise das resoluções do Conselho Municipal de Saúde de Belo Horizonte no período de 1991 a 2010. Ciên Saude Colet 2013;18(8):2401-2411.

29. Cristo SCA. Controle social em saúde: o caso do Pará. Serv Soc e Socie 2012;(109):93-111.

30. Apolinario F. Dicionário de metodologia científica: um guia para a produção do conhecimento científico. São Paulo: Atlas; 2007.

31. Gil AC. Como elaborar projetos de pesquisa. São Paulo: Atlas; 2002.

32. Avritzer L, organizador. A participação social no Nordeste. Belo Horizonte: Editora UFMG; 2007.

Artigo apresentado em 03/10/2017

Aprovado em 30/04/2018

Versão final apresentada em 02/05/2018 